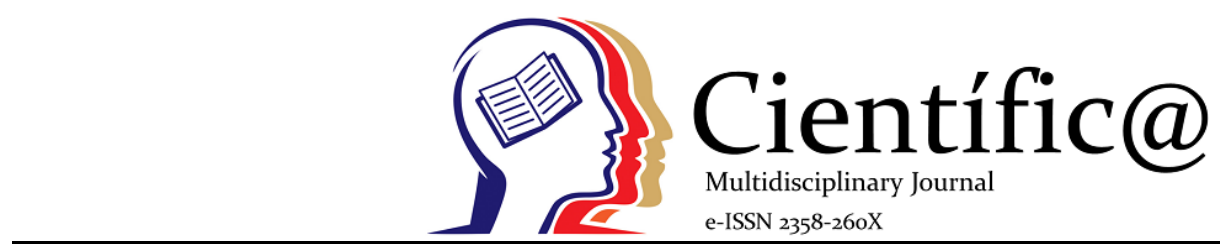

\title{
CONCENTRAÇÕES DE NUTRIENTES NOS TECIDOS DE GRÃOS DE SOJA, INFLUENCIADOS POR FONTES E DOSES FOSFATADAS EM SOLO DE ALTA FERTILIDADE E EM CULTIVO NO CERRADO
}

\author{
NUTRIENT CONCENTRATIONS IN SOYBEAN GRAIN TISSUES INFLUENCED BY SOURCES \\ AND DOSES OF PHOSPHATE IN HIGH FERTILITY SOIL AND IN CERRADO
}

\author{
José Mateus Kondo Santini*1; Salatiér Buzetti²; Adriano Perin3; Carlos Frederico de Souza \\ Castro $^{4}$; Leonnardo Cruvinel Furquim ${ }^{5}$; Daniel Noe Coaguila Nunez ${ }^{6}$; Flávio de Oliveira \\ Silveira7; Luiz César Lopes Filho ${ }^{8}$; Anderson Cruvinel Cabral ${ }^{9}$
}

\author{
${ }^{1}$ Autor para correspondência; Engenheiro Agrônomo, Dr., Professor do Instituto de Ensino Superior de Rio Verde - \\ santini@faculdadeobjetivo.com.br*; \\ 2 Engenheiro Agrônomo, Dr., Professor da Universidade Estadual Paulista - Faculdade de Engenharia de Ilha Solteira- \\ sbuzetti@agr.feis.unesp.br; \\ ${ }^{3}$ Engenheiro Agrônomo, Dr., Professor do Instituto Federal Goiano - Câmpus Rio Verde-perinrj@yahoo.com.br; \\ ${ }^{4}$ Químico, Dr., Professor do Instituto Federal Goiano - Câmpus Rio Verde-carlosfscastro@gmail.com; \\ ${ }^{5}$ Engenheiro Agrônomo, Me. Professor do Instituto de Ensino Superior de Rio Verde- \\ leonnardo.cruvinel@faculdadeobjetivo.com.br; \\ ${ }^{6}$ Biólogo, Dr. Professor do Instituto de Ensino Superior de Rio Verde-tuheraldo@gmail.com; \\ ${ }^{7}$ Engenheiro Agrônomo, Consultor técnico da empresa Exacta-exacta.ai@gmail.com; \\ ${ }^{8}$ Engenheiro Agrônomo Me. Professor do Instituto de Ensino Superior de Rio Verde-lopesfilholuizcesar@gmail.com; \\ ${ }^{9}$ Acadêmico do curso de Engenharia agronômica do Instituto de Ensino Superior de Rio Verde- \\ andersoncruvinelrv@gmail.com.
}

Info

Recebido: $21 / 06 / 2019$

Publicado: $10 / 02 / 2020$

DOI: $10.29247 / 2358-260 X .2019 v 6 i 2 . p 30-37$

ISSN: 2358-260X

Palavras-Chave
Adubos, fertilidade do solo, Glycine max (L.)
Merrill.
Keywords:
Fertilizers, soil fertility, Glycine max (L.)

\begin{abstract}
Resumo
A cultura da soja é uma das principais culturas do agronegócio brasileiro, podendo ser limitada por adubações equivocadas em área de cerrado. Com o presente trabalho, objetivou avaliar a dinâmica da adubação fosfatada, pelo uso de fontes e doses na adubação de manutenção da cultura da soja, em solo com alto teor de $\mathrm{P}$, verificando a real eficácia do uso do superfosfato triplo de eficiência aumentada. 0 experimento foi realizado em delineamento em blocos ao acaso, com quatro repetições, em esquema fatorial de $2 \times 5$, sendo o primeiro fator fontes de fertilizantes (superfosfato triplo e superfosfato triplo de eficiência aumentada) e segundo fator doses de $\mathrm{P}_{2} \mathrm{O}_{5}$ $\left(0,40,80,120\right.$ e $\left.240 \mathrm{~kg} \mathrm{ha}^{-1}\right) .0$ experimento foi conduzido em área experimental, em Rio Verde, GO, buscando-se avaliar as
\end{abstract} influências nas características de componentes de produção e produtividade da soja, bem como, na dinâmica do $\mathrm{P}$ no solo. Constatou-se que a cultura da soja não respondeu à adubação fosfatada, em solo com alto teor de $\mathrm{P}$. 0 uso do Superfosfato triplo de eficiência aumentada não modifica a produtividade de grãos, mas, aumentou a exportação de P via grãos da cultura, em comparação ao Superfosfato Triplo convencional. Para a adubação fosfatada, recomenda-se o uso do Superfosfato triplo convencional na dose de $75 \mathrm{~kg} \mathrm{ha}^{-1} \mathrm{de}_{2} \mathrm{O}_{5}$. 


\section{INTRODUÇÃO}

Nativa da China, a soja (Glycine max (L.) Merrill) é uma cultura pertencente à família Fabaceae (Leguminosa). No Brasil, a oleaginosa destacase dentre as grandes culturas, por sua importância financeira, altas produtividades e ampla área ocupada. Somente esta cultura, segundo o levantamento de dados da Companhia Nacional de Abastecimento (CONAB, 2019), na safra 2018/2019, ocupou $59,2 \%$ de toda área destinada as, com produção de grãos superior a 115 milhões de toneladas.

Para maior incremento de produtividade em solos tropicais, faz-se indispensável o conhecimento sob a fertilidade do solo e a demanda nutricional exigida pela planta. Entre os nutrientes, o fósforo (P) é de suma importância, quanto ao desenvolvimento e a produtividade da soja, por fazer parte de vários processos metabólicos da cultura. Porém, os solos brasileiros são pobres em forma assimilável de P pelas culturas (Sanchez \& Salinas, 1981), fazendo se imprescindível a adubação fosfatada no solo (Van Raij et al., 2001). Visando a melhoria do desenvolvimento da cultura (CHAUDHARY et al., 2008).

O fósforo com seu alto custo e sua baixa eficiência agronômica é frequentemente mencionado com oneroso ao produtor rural. Segundo Van Raij (2004) cerca de $75 \%$ de todo fósforo aplicado e adsorvido ao solo, restando baixo percentual aproveitado pela cultura. Inerente ao baixo aproveitamento de $\mathrm{P}$, o uso de fertilizantes de alta eficiência vem sendo demasiadamente estudados. De acordo com Blaylock (2007) os fertilizantes de eficiência aumentada disponibilizam o nutriente assimilável gradualmente, reduzindo a adsorção do $\mathrm{P}$ no solo, resultando na menor aplicação do nutriente no solo (ZAHRANI, 2000), o que poderiam melhorar a viabilidade da adubação fosfatada para as grandes culturas.
Com presente trabalho objetivou-se avaliar o potencial de fontes e doses de P para a soja cultivada em solos com teor alto de $\mathrm{P}$, na melhora da fertilidade do solo. Verificando qual a fonte mais adequada além de verificar a real eficácia do uso do superfosfato triplo de eficiência aumentada.

\section{MATERIAL E MÉTODOS}

O experimento foi conduzido à campo no município de Rio Verde, GO, com localização geográfica entre os paralelos $20^{\circ} 45^{\prime}$ de latitude sul e $51^{\circ}$ 55 ' de longitude oeste, com altitude de $748 \mathrm{~m}$. A caracterização físico-química apresentou os seguintes valores: $\mathrm{pH}$ (em água) $=5,6 ; \mathrm{MO}=35,0 \mathrm{~g} \mathrm{dm}^{-3} ; \mathrm{P}$ $\left(\right.$ Mehlich I) $=41,0 \mathrm{mg} \mathrm{dm}^{-3} ; \mathrm{K}=6,7 \mathrm{mmol}_{\mathrm{c}} \mathrm{dm}^{-3} ; \mathrm{Ca}=$ $37,8 \mathrm{mmol}_{\mathrm{c}} \mathrm{dm}^{-3} ; \mathrm{Mg}=17,3 \mathrm{mmol}_{\mathrm{c}} \mathrm{dm}^{-3} ; \mathrm{S}=3,1 \mathrm{mg}$ $\mathrm{dm}^{-3} ; \mathrm{Al}=0,0 \mathrm{mmol}_{\mathrm{c}} \mathrm{dm}^{-3} ; \mathrm{V}=53,9 \%$ e textura média (333 $\mathrm{g} \mathrm{kg}^{-1}$ de argila, $166 \mathrm{~g} \mathrm{~kg}^{-1}$ de silte e $501 \mathrm{~g} \mathrm{~kg}^{-1}$ de areia).

A precipitação pluvial acumulada mensal durante o experimento foi de: outubro (2011): $232 \mathrm{~mm}$; novembro (2011): $76 \mathrm{~mm}$; dezembro (2011): $165 \mathrm{~mm}$; janeiro (2012): $275 \mathrm{~mm}$; fevereiro (2012): $265 \mathrm{~mm}$; março (2012): $125 \mathrm{~mm}$.

O experimento foi conduzido em delineamento em blocos ao acaso, com quatro repetições, em esquema fatorial de $2 \times 5$. O primeiro fator foi constituído de fontes de fertilizantes (superfosfato triplo e superfosfato triplo de eficiência aumentada) e o segundo fator doses de aplicação ( 0,40 , 80, 120 e $240 \mathrm{~kg} \mathrm{P}_{2} \mathrm{O}_{5} \mathrm{ha}^{-1}$ ) de fertilizantes fosfatados na semeadura.

Antecedendo a semeadura do experimento realizou-se a dessecação da área, em 21/10/2011, utilizando herbicida glyphosate, na dose de $960 \mathrm{~g}$ i.a ha1. As sementes do cultivar de soja NA 7337 RR foram tratadas com Imidacloprid e Thiamethoxam, ambos na dosagem de $105 \mathrm{~g}$ i.a para cada $100 \mathrm{~kg}$ de sementes de 
soja. Posteriormente, foi realizada a inoculação da soja com Bradyrbizobium japonicum na dosagem de 200 gramas de inoculante (turfa moída) para $40 \mathrm{~kg}$ de sementes, sendo considerada a concentração mínima de $10^{8}$ células viáveis por grama de turfa. Simultaneamente à semeadura foram aplicados $100 \mathrm{~kg} \mathrm{~K}_{2} \mathrm{O} \mathrm{ha}^{-1}$ de, na forma de $\mathrm{KCl}$, e $\mathrm{P}_{2} \mathrm{O}_{5}$ de acordo com cada tratamento.

Cada unidade experimental foi composta por cinco linhas, espaçadas entre si $0,45 \mathrm{~m}$, com cinco metros de comprimento. Considerou-se como área útil da parcela as três fileiras centrais e desprezou-se $0,5 \mathrm{~m}$ das extremidades, totalizanto $5,4 \mathrm{~m}^{2}$. A semeadura foi realizada em 29/10/2011, distribuindo-se 18 sementes por metro no sulco de semeadura, utilizando a semeadora-adubadora.

O controle de plantas daninhas em pósemergência foi realizado com o uso do herbicida glyphosate, na dose de $960 \mathrm{~g}$ i.a ha-1 aos 15 e 40 dias após a emergência (DAE). Também foi realizado o controle da lagarta da soja (Anticarsia gemmatalis) e lagarta falsamedideira (Pseudoplusia includens) aos 45 DAE com Teflubenzurom $\left(50 \mathrm{~mL} \mathrm{ha}^{-1}\right)$. A partir dos $60 \mathrm{DAE}$, procurou-se identificar focos de ferrugem asiática, neste período, foi aplicado o fungicida trifoxystrobin + ciproconazole (300 $\left.\mathrm{mL} \mathrm{ha}^{-1}\right)$, preventivamente, uma vez que a doença não foi encontrada. Doze dias após a primeira aplicação preventiva para controle de ferrugem asiática, outra amostragem foi realizada no experimento e constatado o foco da doença, efetuou-se então, o controle com o fungicida azoxystrobin + ciproconazole $(300 \mathrm{~mL}$ ha-1), realizando essa mesma prática aos $85 \mathrm{DAE}$.

Ao término da colheita da soja, realizou-se a amostragem de solo, de forma aleatória, na camada de 0,00 - 0,20 $\mathrm{m}$ de profundidade, retirando três amostras simples de cada parcela, para formação de amostra composta. Com as amostras retiradas, procedeu-se análises químicas de fertilidade do solo de acordo com Silva (2009).
Para a comparação de médias dos tratamentos, inicialmente, realizou-se o teste de Kolmogorov - Smirnov, buscando avaliar a homocedasticidade (5\%) das variáveis, nos casos em que o $\mathrm{H}_{0}$ foi rejeitado, efetuou a transformação de dados utilizando a equação $(x+0,5)^{0,5}$. Posteriormente, os dados foram submetidos à análise de variância utilizando o pacote ExpDes do software R 3.2.2 programa estatístico R (Ferreira et al., 2011). Quando verificado efeito significativo para as variáveis qualitativas, foi realizada a comparação de médias pelo teste de Tukey $(\mathrm{p}<$ 0,05), já para as variáveis quantitativas foram realizadas regressões polinomiais (de primeiro e segundo grau) à $5 \%$ e $1 \%$ de probabilidade.

\section{RESULTADOS E DISCUSSÃO}

Não foi verificada interação significativa entre fontes e doses avaliadas, nas variáveis dependentes, de química do solo. Não se verificou efeito para as fontes avaliadas (Tabela 1). Já para as doses de P em estudo, sucedeu, de melhor modo, ajustes nos teores de P, S, $\mathrm{Cu}$ e Fe, linearmente, para o P ( $\mathrm{p}<0,01), \mathrm{S}(\mathrm{p}<0,05)$ e Fe ( $p<0,05)$; e quadrático para o $\mathrm{Cu}(\mathrm{p}<0,05)$.

Nas demais variáveis de fertilidade do solo (MOS, pH, V\%, H + Al, Al, SB e CTC) (Tabela 2) houve efeito somente na $\mathrm{V} \%$, para as fontes avaliadas, não ocorrendo efeito para as demais variáveis e possíveis interações. Em avaliação da V\%, verificou-se que o superfosfato triplo convencional (SFTC) foi superior ao superfosfato triplo de eficiência aumentada (SFTEA), com valores, respectivamente, $52,52 \%$ e $50,15 \%$, ou seja, o superfosfato triplo de maior eficiência reduziu em 2,4\% a V\%. 
Tabela 1. Média, desvio padrão amostral (s), coeficiente de variação (CV) e teste $\mathrm{F}$ dos teores de $\mathrm{P}, \mathrm{S}, \mathrm{K}, \mathrm{Ca}, \mathrm{Mg}$, $\mathrm{B}, \mathrm{Cu}, \mathrm{Fe}, \mathrm{Mn}$ e $\mathrm{Zn}$, no solo (0-0,2 m), influenciados por fontes (Superfosfato triplo convencional; Superfosfato triplo revestido por polímeros) e doses $\left(0 ; 40 ; 80 ; 120\right.$; e $\left.240 \mathrm{~kg} \mathrm{P}_{2} \mathrm{O}_{5} \mathrm{ha}^{-1}\right)$ de aplicação de fertilizantes fosfatados, em sulco de semeadura na cultura da soja.

\begin{tabular}{|c|c|c|c|c|c|c|c|c|c|c|}
\hline \multirow{2}{*}{ Variáveis } & $\mathrm{P}$ & $\mathrm{S}$ & K & $\mathrm{Ca}$ & $\mathrm{Mg}$ & B & $\mathrm{Cu}$ & $\mathrm{Fe}$ & $\mathrm{Mn}$ & $\mathrm{Zn}$ \\
\hline & \multicolumn{2}{|c|}{$--\left(\mathrm{mg} \mathrm{dm}^{-3}\right)--$} & \multicolumn{3}{|c|}{----- $\left(\mathrm{mmol}_{\mathrm{c}} \mathrm{dm}^{-3}\right)$----- } & \multicolumn{5}{|c|}{ - $\left(\mathrm{mg} \mathrm{dm}^{-3}\right)$ - } \\
\hline Média & 47,2 & 5,0 & 5,4 & 28,4 & 12,5 & 0,4 & 3,7 & 13,9 & 81,5 & 4,3 \\
\hline$S$ & 14,7 & 0,7 & 0,7 & 2,9 & 1,6 & 0,1 & 0,3 & 1,2 & 5,6 & 0,9 \\
\hline CV $(\%)$ & 31,2 & 14,8 & 13,7 & 10,4 & 12,7 & 15,5 & 6,8 & 8,6 & 6,9 & 21,2 \\
\hline \multicolumn{11}{|c|}{ Teste F } \\
\hline Fontes $(\mathrm{F})$ & $1,03^{\text {ns }}$ & $0,36^{\mathrm{ns}}$ & $0,10^{\mathrm{ns}}$ & $1,78^{\mathrm{ns}}$ & $2,19 \mathrm{~ns}$ & $0,72^{\mathrm{ns}}$ & $0,69^{\mathrm{ns}}$ & $0,63^{\text {ns }}$ & $0,17 \mathrm{~ns}$ & $0,16^{\mathrm{ns}}$ \\
\hline Doses $\mathrm{x}$ & $12,18^{* *}$ & $4,92^{*}$ & $0,73^{\text {ns }}$ & $0,01^{\mathrm{ns}}$ & $0,42^{\text {ns }}$ & $2,73^{\text {ns }}$ & $3,36^{\text {ns }}$ & $7,28^{* *}$ & $0,62^{\mathrm{ns}}$ & $0,21^{\text {ns }}$ \\
\hline (D) $x^{2}$ & $5,97^{* *}$ & $2,70^{\text {ns }}$ & $0,71^{\mathrm{ns}}$ & $1,63^{\text {ns }}$ & $0,30^{\text {ns }}$ & $1,46^{\mathrm{ns}}$ & $4,86^{*}$ & $3,58^{*}$ & $0,07^{\text {ns }}$ & $1,45^{\text {ns }}$ \\
\hline$F \times D$ & $0,52^{\text {ns }}$ & $0,97^{\mathrm{ns}}$ & $0,37^{\mathrm{ns}}$ & $1,75^{\mathrm{ns}}$ & $0,54^{\mathrm{ns}}$ & $0,59^{\mathrm{ns}}$ & $0,15^{\text {ns }}$ & $0,62^{\text {ns }}$ & $0,46^{\text {ns }}$ & $0,31^{\mathrm{ns}}$ \\
\hline
\end{tabular}

ns: Não significativo; ${ }^{*, *}$ : Significativo a $5 \%$ e $1 \%$, respectivamente.

Tabela 2. Média, desvio padrão amostral (s), coeficiente de variação $(\mathrm{CV})$ e teste $\mathrm{F}$ do teor de matéria orgânica (M.O.), pH, Saturação por bases (V\%), H + Al, Al, soma de bases (SB) e capacidade de troca catiônica (CTC) no solo $(0-0,2 \mathrm{~m})$, submetidos a fontes (Superfosfato triplo convencional; Superfosfato triplo revestido por polímeros) e doses (0; 40; 80; 120; e $\left.240 \mathrm{~kg} \mathrm{P}_{2} \mathrm{O}_{5} \mathrm{ha}^{-1}\right)$ de aplicação de fertilizantes fosfatados, em sulco de semeadura, na cultura da soja.

\begin{tabular}{|c|c|c|c|c|c|c|c|}
\hline \multirow{2}{*}{ Variáveis } & M.O. & $\mathrm{pH}$ & $\mathrm{V} \%$ & $\mathrm{H}+\mathrm{Al}$ & $\mathrm{Al}$ & $\mathrm{Sb}$ & CTC \\
\hline & $\left(\mathrm{g} \mathrm{dm}^{-3}\right)$ & $\left(\mathrm{CaCl}_{2}\right)$ & $(\%)$ & \multicolumn{4}{|c|}{$\left.-\mathrm{mmol}_{\mathrm{c}} \mathrm{dm}^{-3}\right)^{-}$} \\
\hline Média & 29,6 & 5,1 & 51,3 & 44,0 & 0,6 & 44,8 & 90,3 \\
\hline $\mathrm{s}$ & 1,6 & 0,1 & 3,8 & 4,3 & 0,2 & 8,0 & 5,2 \\
\hline CV $(\%)$ & 5,3 & 1,8 & 7,5 & 9,8 & 32,7 & 17,8 & 5,7 \\
\hline \multicolumn{8}{|c|}{ Teste F } \\
\hline Fontes $(\mathrm{F})$ & $0,000^{\text {ns }}$ & $0,516^{\mathrm{ns}}$ & $4,373^{*}$ & $3,031^{\text {ns }}$ & $0,176^{\mathrm{ns}}$ & $0,245^{\text {ns }}$ & $0,052^{\mathrm{ns}}$ \\
\hline \multirow{3}{*}{ 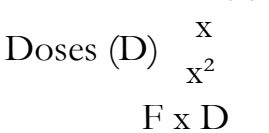 } & $3,117^{\mathrm{ns}}$ & $0,022^{\mathrm{ns}}$ & $0,606^{\mathrm{ns}}$ & $1,530^{\mathrm{ns}}$ & $1,079^{\mathrm{ns}}$ & $0,136^{\mathrm{ns}}$ & $1,012^{\mathrm{ns}}$ \\
\hline & $3,107^{\prime n s}$ & $0,011^{\mathrm{ns}}$ & $1,350^{\mathrm{ns}}$ & $0,970^{\text {ns }}$ & $0,947^{\mathrm{ns}}$ & $0,325^{\mathrm{ns}}$ & $0,753^{\mathrm{ns}}$ \\
\hline & $0,953^{\text {ns }}$ & $2,667^{\mathrm{ns}}$ & $1,518^{\mathrm{ns}}$ & $0,905^{\text {ns }}$ & $1,500^{\mathrm{ns}}$ & $2,195^{\mathrm{ns}}$ & $0,025^{\mathrm{ns}}$ \\
\hline
\end{tabular}

ns: Não significativo.

Os resultados significativos para as doses avaliadas, já supracitados, encontram-se dispostos na Tabela 3. Como já hipotetizado, nota-se, pelos resultados, que o uso das doses de $\mathrm{P}_{2} \mathrm{O}_{5}$ correlaciona-se com os aumentos dos teores de P do solo. No presente estudo, as doses ajustaram linearmente, resultando no incremento de, aproximadamente, $20,9 \mathrm{mg} \mathrm{dm}^{-3}$ de $\mathrm{P}$ (aproximadamente 53,7\%), quando comparada a não adubação (controle; $0 \mathrm{~kg} \mathrm{ha}^{-1}$ de $\mathrm{P}_{2} \mathrm{O}_{5}$ ) com a maior dose testada (240 kg ha-1 de $\left.\mathrm{P}_{2} \mathrm{O}_{5}\right)$.

O S e o Fe ajustaram linearmente, nas doses estudas, com incrementos, respectivos, de $0,67 \mathrm{mg} \mathrm{dm}-$ ${ }^{3}(14,3 \%)$ e $1,44 \mathrm{mg} \mathrm{dm}^{-3}(10,8 \%)$, quando comparada a não adubação (controle; $0 \mathrm{~kg} \mathrm{ha}^{-1}$ de $\mathrm{P}_{2} \mathrm{O}_{5}$ ) com a maior dose testada (240 kg ha-1 $\left.\mathrm{de}_{2} \mathrm{O}_{5}\right)$. 
Tabela 3. Teores de $\mathrm{P}, \mathrm{S}$, Cu e Fe, na fertilidade do solo $(0-0,2 \mathrm{~m})$, e concentração de $\mathrm{N}$ e Fe, nos grãos colhidos de soja, submetidos às doses $\left(0 ; 40 ; 80 ; 120\right.$; e $240 \mathrm{~kg} \mathrm{P}_{2} \mathrm{O}_{5}[\mathrm{P}]$ ha $\left.^{-1}\right)$ de adubação fosfatada, com seus respectivos ajustes e coeficiente de determinação $\left(\mathrm{R}^{2}\right)$.

\begin{tabular}{|c|c|c|c|c|c|c|c|c|c|}
\hline \multirow{2}{*}{\multicolumn{3}{|c|}{ Variáveis }} & \multicolumn{5}{|c|}{ Doses $\left(\mathrm{kg} \mathrm{P}_{2} \mathrm{O}_{5} \mathrm{ha}^{-1}\right)$} & \multirow[t]{2}{*}{ Ajuste } & \multirow[t]{2}{*}{$\mathrm{R}^{2}$} \\
\hline & & & 0 & 40 & 80 & 120 & 240 & & \\
\hline \multirow{4}{*}{ Solo } & $\mathrm{P}$ & & 41,8 & 40,1 & 40,8 & 53,9 & 59,5 & $\mathrm{P}_{\text {solo }}=0,0871 \mathrm{P}+38,84$ & 0,8110 \\
\hline & S & $\exists$ & 4,8 & 4,8 & 5,1 & 4,7 & 5,5 & $\mathrm{~S}=0,003 \mathrm{P}+4,68$ & 0,6439 \\
\hline & $\mathrm{Cu}$ & $\infty$ & 3,5 & 3,8 & 3,7 & 3,9 & 3,8 & $\mathrm{Cu}=-0,00001 \mathrm{P}^{2}+0,0044 \mathrm{P}+3,54$ & 0,7334 \\
\hline & $\mathrm{Fe}$ & & 13,0 & 14,1 & 13,9 & 13,8 & 14,8 & $\mathrm{Fe}=0,006 \mathrm{P}+13,35$ & 0,7241 \\
\hline
\end{tabular}

Os teores de $\mathrm{Cu}$ ajustaram de modo quadrático, com valores de máxima estimada na dose de $220 \mathrm{~kg}$ ha ${ }^{1}$ de $\mathrm{P}_{2} \mathrm{O}_{5}$. Na referida dose, verificou-se incremento, quando comparado a não adubação (controle; $0 \mathrm{~kg} \mathrm{ha}^{-1}$ de $\mathrm{P}_{2} \mathrm{O}_{5}$ ), de $0,5 \mathrm{mg} \mathrm{dm}^{-3}$, valor que representa $13,7 \%$ a mais de Cu disponível no solo.

Nas análises das variáveis referente à fertilidade do solo (Tabela 1; 2), em geral, poucos efeitos foram encontrados. Tais ausências eram esperadas para a maioria dos nutrientes, já que grande parte dos nutrientes analisados têm comportamento distintos ao do P e não competem tanto na absorção do nutriente como em sua dinâmica no solo. Já o aumento no teor de P disponível do solo (Tabela 1) esperava-se o efeito, pela dose máxima testada $\left(240 \mathrm{~kg} \mathrm{P}_{2} \mathrm{O}_{5} \mathrm{ha}^{-1}\right)$, assim, o aumento na dose de aplicação de $\mathrm{P}$ resulta na maior disponibilidade do nutriente.

$\mathrm{Na}$ hipótese do presente estudo, esperava-se maior eficiência do fertilizante de eficiência aumentada (SFTEA), no que se tange aos teores de $\mathrm{P}$ no solo, porém, verificou-se que não houve diferença entre as fontes avaliadas. Na literatura, estudos com o uso de fontes fosfatadas de eficiência aumentada, encontra-se divergência na real eficácia dessa tecnologia. Com trabalhos demonstrando a maior eficiência dos fertilizantes de eficiência aumentada, como observado por Figueiredo et al., 2012; Santini et al., 2013; e Souza et al., 2014, mas, também, existem trabalhos sem diferenciação das fontes fosfatadas, como concluído por Valderrama et al., 2009; Valderrama et al., 2011; e Gazola et al., 2013.

O aumento no teor de S na solução do solo (Tabela 2) é explicado por Richart et al. (2006), onde os autores encontraram resultado semelhante e atribuíram o aumento de $\mathrm{S}$ no solo pelo deslocamento do sulfato, para a solução, ocasionado fosfato aplicado, ou seja, com a aplicação do fertilizante fosfatado, $\mathrm{O}_{2} \mathrm{H}_{2} \mathrm{PO}_{4}^{-}$ ocupa os sítios de trocas aniônicas, antes ocupado pode $\mathrm{SO}_{4}^{2-}$, resultando em sua desorção.

Os ajustes encontrados para o $\mathrm{Cu}$ e Fe (Tabela 1), inicialmente, foram relacionados à redução do $\mathrm{pH}$ pelo uso dos adubos fosfatados, todavia, a redução de $\mathrm{pH}$ por fertilizantes fosfatados, quando comparado com outros fertilizantes, são quantitativamente baixas. De acordo com Korndörfer e Sousa (2010), o superfosfato triplo tem pouco efeito na reação do $\mathrm{pH}$ do solo, já que se trata de uma fonte bem curada. Somando a este fato, se o aumento dos micronutrientes, supracitados, fossem exclusivamente resultantes de tal processo (redução de $\mathrm{pH}$ ), era-se esperado que ocorresse, também, para os demais micronutrientes catiônicos (Mn e Zn) (Lindsay, 1972). Assim, é possível que o aumento do teor de $\mathrm{Cu}$ e $\mathrm{Fe}$, seja também, relacionados a outros fatores, como impurezas nos fertilizantes.

Carvalho et al. (2012), em estudo com aporte de micronutrientes por fertilizantes e corretivos, observaram que dos 24 fertilizantes fosfatados testados, 
em média, os fertilizantes possuíam concentração de $1.552,8$ e $222,7 \mathrm{mg} \mathrm{kg}^{-1}$, respectivamente para o Fe e Cu. No entanto, quando comparado os valores dos autores a cima, com o do presente trabalho, é notório que o aumento do teor de $\mathrm{Cu}$ e Fe não é somente pelo aporte dos micronutrientes pelos fertilizantes fosfatados, bem como pela redução do pH.

A outra hipótese, para exemplificação dos resultados obtidos, é pelo aumento da velocidade de transformação do material orgânico para matéria orgânica do solo (MOS), devido ao uso do P (advindo dos fertilizantes) pelos microrganismos presente no solo, ou seja, com maior quantidade de material orgânico mineralizado e transformado em MOS, maiores concentrações de nutrientes foram disponibilizadas na solução do solo. Está hipótese é sustentada por Siqueira et al. (1994), com os autores mencionando que o P inorgânico do solo é utilizado, principalmente, para o crescimento microbiano. Assim, quando mensurado o uso de P pela microbiota, Oliveira et al. (2011) constataram que a microbiota do solo possuía valor médio do $\mathrm{P}$, de 28,3 $\mathrm{mg} \mathrm{kg}^{-1}$, valor 24,6 vezes maior que o P do solo disponível (em média 1,1 $\left.\mathrm{mg} \mathrm{kg}{ }^{-1}\right)$.

De acordo com a Embrapa (2011), para cada $\mathrm{Mg}$ produzida de MS, a soja retorna, na forma de restos culturais, 16 g e 390 g, respectivamente de $\mathrm{Cu}$ e Fe, estimando-se que em R1, os restos culturais do presente trabalho (2,5 $\mathrm{Mg} \mathrm{ha}^{-1}$ de $\left.\mathrm{MS}\right)$ resultariam na mineralização de 41 g e 990 g, respectivamente de Cu e Fe.

Entretanto, como notado nos resultados da Tabela 3, não houve efeito significativo da MOS, na significância adotada no presente trabalho $(\mathrm{p}<0,05)$, mas, quando analisado com maior significância ( $\mathrm{p}<$ 0,10), verificou-se ajuste quadrático para a variável de MOS, com aumento de $1,7 \mathrm{~g} \mathrm{dm}^{-3}$, quando comparado $0 \mathrm{~kg}$ de $\mathrm{P}_{2} \mathrm{O}_{5} \mathrm{ha}^{-1}$ com a dose de $155 \mathrm{~kg} \mathrm{P}_{2} \mathrm{O}_{5} \mathrm{ha}^{-1}$ (dose de máxima eficiência estimada). A opção da utilização da maior significância para a MOS, foi de única e exclusiva, para melhor compreensão das variáveis de teores de $\mathrm{Cu}$ e Fe do solo.

Diante o exposto, compreende-se que o aumento dos teores de $\mathrm{Cu}$ e Fe disponíveis, ocorreram em função da somatória de fatores resultantes da adubação fosfatada, sendo eles: redução de pH; aporte via fertilizante fosfatado; e aceleração da transformação da MOS.

Os efeitos de redução da V\% (Tabela 2), pelo uso do superfosfato triplo de maior eficiência, foi atribuída a acidez potencial $(\mathrm{H}+\mathrm{Al})$, mesmo não sendo verificado efeito para o $\mathrm{H}+\mathrm{Al}$ no presente trabalho, à significância de 5\%. Porém, quando analisada a variável em maior significância $(\mathrm{p}<0,10 \%)$, notou-se efeito significativo, com o SFTR 2,4 $\mathrm{mmol}_{\mathrm{c}} \mathrm{dm}^{-3}$ superior ao SFTC, este fato, somando com a redução (significância superior ao 5\%) dos teores de Ca $(\mathrm{p}<0,2)$ e $\mathrm{Mg}(\mathrm{p}<$ $0,15)$, resultou nos efeitos observados na $\mathrm{V} \%$.

Como a $\mathrm{V} \%$ é o produto final entre relações das concentrações de cátions no solo $(\mathrm{H}, \mathrm{Al}, \mathrm{Ca}, \mathrm{Mg}$, $\mathrm{K})$, alterações nas concentrações dos mesmos, refletem diretamente na $\mathrm{V} \%$. Devido a este fato, com menores significância $(\mathrm{p}<0,05)$ pode-se verificar efeito na $\mathrm{V} \%$. Diferentemente, para os cátions presente no solo, farse-á necessárias maiores significâncias ou maiores alterações para observação de efeitos significativos. Assim, também, optou-se na utilização de maiores significâncias, para explanação dos resultados encontrados da $\mathrm{V} \%$, nas variáveis que poderiam influenciar na mesma. Sobretudo, se deve destacar, que na literatura científica há poucos trabalhos inerentes a fertilizantes de eficiência aumentada, tratando-se da fertilidade do solo, assim sendo, torna-se de difícil comparação com os resultados do presente trabalho.

\section{CONCLUSÃO}


O Superfosfato triplo convencional é a melhor opção de aplicação, comparativamente ao superfosfato triplo de eficiência aumentada, devido a não diferença entre as fontes e ao fato do fertilizante convencional possuir melhor relação custo-benefício.

A adição de $\mathrm{P}$ no solo, via fertilizante, promoveu melhorias nos teores de P, S, Cu, Fe e MOS do solo.

\section{REFERÊNCIAS}

Blaylock A. O futuro dos fertilizantes nitrogenados de liberação controlada. Informações agronômicas. 2007;120(1):08-10.

Carvalho VGB, Nascimento CWA, Biondi CM. Potencial de fertilizantes e corretivos no aporte de micronutrientes ao solo. Revista Brasileira de Ciência do Solo. 2012; 36:931-938.

Chaudhary, M. I.; Adu-Gyamfi, J. J.; Saneaka, H.; Ngguyen, N. T.; Suwa, R.; Kanai, S.; El-Shemy, H. A.; Lightfoot, D. A.; Fujita, K. The effect of phosphorus deficiency on nutrient uptake, nitrogen fixation and photosynthetic rate in mashbean, mungbean and soybean. Acta Physiology Plant, v. 30, p. 537-544, 2008.

CONAB - Companhia Nacional de Abastecimento. Acompanhamento da Safra Brasileira: Grãos. Safra 2018/19 - Décimo segundo levantamento. Brasília, V.6, N.12, p.14-16 2019.

Empresa Brasileira de Pesquisa Agropecuária (EMBRAPA). Tecnologias de produção de soja - região central do Brasil 2012 e 2013. EMBRAPA, Londrina, Brasil. 261 p.; 2011.

Ferreira DF.Sisvar: a computer statistical analysis system. Ciência e Agrotecnologia. 2011; 35(6):10391042.

Figueiredo CC, Barbosa DV, Oliveira AS, Fagioli M, Sato JH. Adubo fosfatado revestido com polímero e calagem na produção e parâmetros morfológicos de milho. Revista Ciência Agronômica. 2012; 43(3):446-452.

Gazola RN, Buzetti S, Dinalli RP, Teixeira Filho MCM, Celestrino TS. Efeito residual da aplicação de fosfato monoamônio revestido por diferentes polímeros na cultura de milho. Revista Ceres. 2013; 60(6):876-884.

Korndörfer GH, Sousa RTX. Recuperação do fósforo aplicado no solo de fontes solúveis e insolúveis em água. Enciclopédia biosfera, Centro Cientifico Conhecer. 2010; 6(11):9-15.

Lindsay WL. Inorganic phase equilibria of micronutrients in soils. In: Mortvedt JJ, Giordano PM, Lindsay WL (eds.) Micronutrients in agriculture. Soil Science Society of America, Madison, USA. 760 p.; 1972.

Oliveira LB, Tiecher T, Quadros FLF, Santos DR. Fósforo microbiano em solos sob pastagem natural submetida à queima e pastejo. Revista Brasileira de Ciência do Solo. 2011; 35:1509-1515.

Van Raij B. van. Fósforo no solo e interação com outros elementos. Fósforo na agricultura brasileira. Piracicaba: POTAFÓS, p. 435-456, 2004.

Van Raij B, Andrade JC, Cantarella H, Quaggio JÁ. Análise química para avaliação da fertilidade de solos tropicais. Instituto Agronômico de Campinas, Campinas, Brasil. 285 p.; 2001.

Richart A, LanaMC, Schulz LR, Bertoni JC, Braccini AL. Disponibilidade de fósforo e enxofre para a cultura da soja na presença de fosfato natural reativo, superfosfato triplo e enxofre elementar. Revista Brasileira de Ciência do Solo. 2006; 30(4):695705.

Sanchez, P.A. \& Salinas, J.G. Low input technology for managing Oxisols and Ultisols in tropical America. Adv. Agron., 1981; 34:280-406.

Santini JMK, Perin A, Silveira FO, Lopes Filho LC, Valderram M. The usage of NPK coated by polymers on the cotton crop (GOSSYPIUM HIRSUTUM L.) For biomass production on the aerial part. Global Science and Technology. 2013; 6(3):79-89.

Siqueira JO, Moreira FMS, Grisi BM, Hungria M, Araujo RS. Microrganismos e processos biológicos do solo: perspectiva ambiental. EMBRAPA, Brasília, Brasil. 142 p.; 1994.

Souza JR, Ribeiro BN, Raposo TP, Fiorin JE, Castro GSA, Magalhães RS. Eficiência do fósforo 
revestido com polímeros na cultura da soja Acta Ignazu, 2014.

Valderrama M, Buzetti S, Benett CGS, Andreotti M, Alf $\mathrm{O}$, Eustaquio SM. Fontes e doses de nitrogênio e fósforo em feijoeiro no sistema plantio direto Pesquisa Agropecuária Tropical. 2009; 39(3):191-196

Valderrama M, Buzetti S, Benett CGS, Andreotti M, Teixeira Filho MCM. Fontes e doses de NPK em milho irrigado sob plantio direto Pesquisa Agropecuária Tropical. 2011; 41:(2):254-263

Zahrani, S. Utilization of polyethylene and paraffin waxes as controlled delivery systems for different fertilizers. Industrial \& Engineering Chemistry Research, Washington, v.39, n.3, p.367-371, 2000 . 